\title{
A los revisores: actuales y futuros.
}

\author{
To current and future reviewers
}

\author{
Silvana Sarabia ${ }^{1}$
}

Los editores de la Revista de Neuro-Psiquiatría queremos manifestar nuestra gratitud a todos los revisores que colaboraron en el 2011, apreciando su esfuerzo y generosidad al brindar su tiempo y compartir su enriquecedor conocimiento en nuestras publicaciones. Las revistas científicas no podrían subsistir sin la labor dedicada y desinteresada de sus revisores, encargados tácitos de la protección permanente de la calidad editorial a la que todos aspiramos.

La revisión de un manuscrito implica varias responsabilidades: evaluar, verificar, mejorar el artículo, educar a los autores y editores, y expresar opiniones expertas. Además, la revisión debe ser trasmitida de una manera respetuosa, imparcial y a tiempo (1), siendo este último detalle tan importante como los otros. Los editores usualmente escogen a los revisores, en base a su experiencia en determinada área, su disponibilidad, su rectitud e integridad, ya que la revisión no es solo un proceso técnico sino, fundamentalmente, un juicio ético. Revisar un artículo es un privilegio pero también un compromiso que requiere habilidad, dedicación y experiencia que conduzcan a un dictamen completo, calificado y justo. Los conocedores describen algunas estrategias que pueden ser útiles para mejorar las destrezas de aquellos que empiezan su contribución profesional como revisores: conocimiento preciso de su papel, auto-evaluación honesta de su experiencia, familiaridad con el estilo de la revista, declaración explícita de posibles conflictos de interés, revisión sistemática de los criterios de revisión establecidos por la revista, estructuración del informe de acuerdo a las normas establecidas y cumplimiento de los plazos requeridos (2). La mayoría de los revisores de artículos se hacen tales no a través de un adiestramiento formal sino al llevar apropiadamente a cabo la tarea misma. En un ensayo de muestras aleatorias donde la hipótesis era que la calidad de las revisiones posteriores de un manuscrito específico mejoraría si los revisores novatos eran asesorados por revisores experimentados, se concluyó que el entrenamiento así estructurado no mejoraba la calidad de las revisiones posteriores (3). Como cualquier otra habilidad, el "arte" de revisar manuscritos se adquiere y perfecciona con la práctica.

En la Revista de Neuro-Psiquiatría, al igual que en muchas de las revistas científicas, la revisión, esto es, el control de calidad de los artículos es un proceso confidencial y anónimo; a los autores no se les dice quiénes son sus revisores, y los revisores desconocen quiénes son los autores. Sin embargo hay otras revistas, como las series de BioMed Central, donde este proceso es abierto, no solo se conoce quiénes son los revisores, sino que se publica el proceso de revisión (4). En ambos casos los "auditores" serían todos los lectores y todos aquellos que envían cartas al editor expresando su acuerdo o desacuerdo con el material publicado. Aun cuando todos los lectores tienen la posibilidad de ser auditores, es necesario reconocer que muy pocos hacen uso de este valioso recurso.

Hacemos propicia la oportunidad para reiterar este pedido a colegas psiquiatras, neurólogos y otros profesionales interesados en la continua mejora de nuestra publicación.

1 Editora Jefa, Revista de Neuro-Psiquiatría. Docente, Sección Académica de Psiquiatría y Salud Mental, Departamento Académico de Clínicas Médicas, Facultad de Medicina Alberto Hurtado. Universidad Peruana Cayetano Heredia. Lima, Perú. 
Es importante recordar que al revisor se le pide que emita una opinión informada sobre el artículo. La decisión final de si el manuscrito se publica o no, es usualmente función de los editores. Estos deben ser capaces de discernir con precisión las ideas de cada revisor y buscar un balance entre sus opiniones y comentarios con los de otros revisores y los suyos propios (4). Los editores apreciamos las evaluaciones que nos ayudan a garantizar a los lectores la idoneidad de la información y de los datos a ser publicados.

Esta nota editorial, además de expresar nuestra gratitud a los revisores que nos han acompañado durante el año pasado, es también una invitación a futuros colaboradores en esta tarea, a todos aquellos que deseen iniciar su experiencia en la revisión de artículos científicos, un delicado y valioso componente de toda labor editorial.

\section{REFERENCIAS BIBLIOGRÁFICAS}

1. Alenxandrov AV, Hennerici MG, Norving B. Suggestions for reviewing manuscripts. Cerebrovasc Dis. 2009; 28:243-246.

2. Azer SA, Ramani S, Peterson R. Becoming a peer reviewer to medical education journals. Med Teach. 2012; 34: 698-704.
3. Houry D, Green S, Callaham M. Does mentoring new peer reviewers improve review quality? A randomized trial. BMC Med Educ. 2012; 12:83.

4. Benos DJ, Kirk KL, Hall JE. How to review a paper. Advan in Physiol Educ. 2003; 27:47-52. 